\title{
Sleep Patterns in Adolescents with Hypertension
}

\author{
Irina M. Madaeva, $\mathrm{PhD}, \mathrm{ScD}$; Olga N. Berdina, $\mathrm{PhD}$ *; Tamara Mandzyak, $\mathrm{PhD}$; \\ Sergey Kolesnikov, PhD, ScD; Liubov I. Kolesnikova, $\mathrm{PhD}, \mathrm{ScD}$ \\ Scientific Centre for Family Health and Human Reproduction Problems \\ Irkutsk, the Russian Federation
}

\begin{abstract}
Background: There is growing evidence that psychological stress contributes to hypertension and leads to changes in sleep structure. Insufficient sleep may lead to cardiovascular disease. Thus, the aim of this study was to explore specific sleep patterns in adolescents with hypertension.

Methods: The study population consisted of 35 young patients (14-17 years old): 20 adolescents with hypertension and 15 healthy adolescents. Polysomnography (PSG) was performed on all patients.

Results: Statistical analysis showed significant changes of sleep patterns in the hypertensive adolescents compared to the normotensive adolescents. Hypertension was associated with significantly decreased slow wave sleep (16.86 \pm 0.3 vs. $22.7 \pm 0.3 \%$; $P<0.05)$ and increased rapid eye movement sleep (REM) $(23.1 \pm 0.2$ vs. $30.75 \pm 0.2 \% ; P<0.05)$. At the same time, sleep latency increased compared to subjects without hypertension $(27.2 \pm 0.3$ vs. $11.2 \pm 0.4 \mathrm{~min}, P<0.05$ ). Wake time after sleep onset (WASO) was also significantly $(19.1 \pm 0.2$ vs. $5.9 \pm 0.3 \mathrm{~min}, P<0.05)$ longer than in healthy adolescents, which led to reduced sleep duration.

Conclusion: These results suggest that these kinds of sleep deviations are closely associated with some adaptive reaction to prolonged exposure of psychogenic factors in the hypertensive adolescents. (Int J Biomed. 2016;6(1):53-55.).
\end{abstract}

Keywords: sleep; polysomnography; adolescents; hypertension.

\section{Introduction}

Hypertension is a leading public health challenge globally due to its high prevalence and related morbidity and mortality [1]. The roots of hypertension in adulthood extend back to childhood. That is to say, children and adolescents with elevated blood pressure (BP) are more likely to become hypertensive adults [2,3]. There is growing evidence that psychological stress contributes to hypertension and cardiovascular disease [4]. A number of authors have shown that onset of hypertension corresponds to some level of insufficiency of psychophysiological regulation and could be driven by different neurogenic and psychogenic factors [5]. Blood pressure (BP) level correlates with the emotional status, level of anxiety, individual reactions to stressful situations, personal features, and mental status. Clinical data suggest raised reactivity of the cardiovascular system, which appears as an increasing heart rate and elevated BP

*Corresponding author: Olga Berdina, PhD. Scientific Centre for Family Health and Human Reproduction Problems, Irkutsk, Russia.E-mail: goodnight84@mail.ru in response to stress or other factors [6]. In addition, it is known that stress leads to changes in sleep structure $[7,8]$. However, sleep is a process that depends on conditions in the brain that integrate, differentiate and coordinate all personal psychosomatic activity [9]. Insufficient sleep impairs physical and psychological development, which may negatively affect concentration, performance, behavior, emotional well-being, and overall health.

The precise biological mechanisms are only partially understood, but the autonomic nervous system could be a potential pathway linking sleep problems with subsequent pathologies such as hypertension, diabetes, and cardiovascular disease [10-12]. It has been shown that rapid eye movement sleep (REM) is the main sleep pattern connected to psychic adaptation and emotional recovery [13].

Thus, analysis of sleep patterns in adolescents with hypertension can help either to detect how this pathogenic factor drives sleep structure to change and evaluate types of adaptive reactions in these patients.

The aim of this study was to explore specific sleep patterns in adolescents with hypertension. 


\section{Materials and Methods}

The study included a cohort of 35 subjects (age range 14-17 years). All patients were divided into 2 groups. Group 1 consisted of 20 patients with hypertension, and Group 2 of 15 healthy adolescents. Hypertension in children and adolescents continues to be defined as systolic BP (SBP) and/or diastolic BP (DBP), that is, on three separate measurements, at or above the 95th percentile (The fourth report on the Diagnosis, Evaluation, and Treatment of High Blood Pressure in Children and Adolescents, 2005)

Adolescents were invited to undergo a full night of PSG recording. This study was approved by the Ethics Committee of the Scientific Centre for Family Health and Human Reproduction Problems Local Ethical committee and a written informed consent was obtained from all participants or their parents (if a child under 15 years old) at the assessment.

During a visit to the Somnological Center, trained technicians equipped the subjects with the Polysomnography (PSG) recorder (GRASS-TELEFACTOR Twin PSG-system with As 40 booster and integrated sleep-module SPM-1, USA) between 20:00 and 22:00. All sleep recordings took place in the special room and included a total of 18 channels: six electroencephalography, two electrooculography, three surface electromyography (one submental, two for right and left anterior tibialis muscles), one for electrocardiogram, nasal pressure, thoracic and abdominal belts, body position, oxygen saturation, and pulse rate. During the study, all patients were under observation by trained sleep technicians. We also used an infrared camera for night video monitoring. All PSG recordings were visually scored by a trained sleep physician. Sleep stages, leg movements, and arousals were scored according to the 2007 American Academy of Sleep Medicine (AASM) criteria [14].

The statistical analysis was performed using the statistical software Statistica v6.0 (StatSoft, USA). The mean $(M)$ and standard error of the mean (SEM) were calculated. For data with normal distribution, inter-group comparisons were performed using Student's t-test. Differences of continuous variables departing from the normal distribution were tested by the Mann-Whitney $U$-test. A probability value of $P<0.05$ was considered statistically significant.

\section{Results}

Table 1 presents the sleep characteristics according to the absence or presence of hypertension in adolescents. Statistical analysis showed significant differences in sleep structure between patients in the two groups.

In Group 1, in spite of relatively preserved cyclic sleep and balanced sleep phases, there was alteration in the normal duration of sleep phases (Figure 1). Hypertension was associated with significantly decreased slow wave sleep $(16.86 \pm 0.3$ vs. $22.7 \pm 0.3 \% ; P<0.05)$ and increased REM ( $23.1 \pm 0.2$ vs. $30.75 \pm 0.2 \% ; P<0.05)$. At the same time, sleep latency increased compared to subjects without hypertension (27.2 \pm 0.3 vs. $11.2 \pm 0.4 \mathrm{~min}, P<0.05)$. Wake time after sleep onset (WASO) was also significantly ( $19.1 \pm 0.2$ vs. $5.9 \pm 0.3$ min, $P<0.05)$ longer than in healthy adolescents, which led to reduced sleep duration. There were no-significant differences between the two groups in the amount of arousals; however, there was a tendency to increased arousals in hypertensive subjects.

Table 1.

Sleep characteristics according to the absence or presence of hypertension in adolescents

\begin{tabular}{|l|c|c|c|}
\hline \multicolumn{1}{|c|}{ Variable } & $\begin{array}{c}\text { Group 1 } \\
(\mathrm{n}=20)\end{array}$ & $\begin{array}{c}\text { Group 2 } \\
(\mathrm{n}=15)\end{array}$ & $P$ \\
\hline Total sleep time (TST), min & $402 \pm 3$ & $400 \pm 2$ & 0.53 \\
\hline Superficial sleep, \% of TST & $51.8 \pm 0.3$ & $54.2 \pm 0.25$ & 0.21 \\
\hline Slowly-wave sleep, \% of TST & $16.86 \pm 0.3$ & $22.7 \pm 0.3$ & $<0.05$ \\
\hline REM, \% of TST & $30.75 \pm 0.2$ & $23.1 \pm 0.2$ & $<0.05$ \\
\hline Sleep latency, min & $27.2 \pm 0.3$ & $11.2 \pm 04$ & $<0.05$ \\
\hline WASO, min & $19.1 \pm 0.2$ & $5.9 \pm 0.3$ & $<0.05$ \\
\hline Arousal index, $\mathrm{n} / \mathrm{h}$ & $18.45 \pm 0.4$ & $15.2 \pm 0.3$ & 0.18 \\
\hline
\end{tabular}

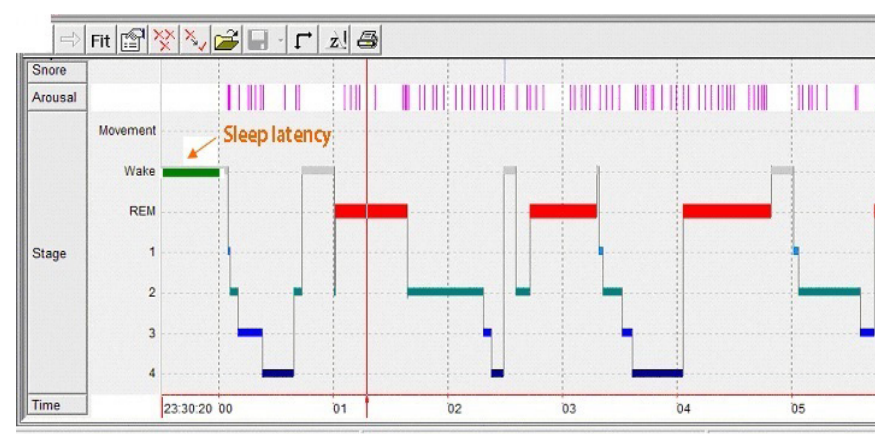

Fig. 1. The sleep histogram of 15-year-old patient with hypertension

Sleep latency from 11.30 PMuntil 12.05 AMis marked. Cyclicity of sleep is kept, however, insignificant reduction duration of slow wave sleep (SWS) (stages 3, 4) due to considerable increase of REM sleep is observed. In addition, it is marked increase of the period of wakefulness overnight (Wake).

\section{Discussion}

In the modern informational space with a high educational requirement, adolescents are exposed to daily life stress in the home or school environment. The initial deficiency of psychophysiological regulation and chronic stress can lead to activation of the neuroendocrine and immune systems (sympathetic nervous system, hypothalamus-pituitaryadrenal axis, and cytokines) and confer related cardiovascular risks $[15,16]$. We suppose that detected specific sleep patterns in adolescents with hypertension indicate some adaptive reorganization of the psychophysiological system. Difficulties falling asleep, an increasing WASO, and a tendency to an increase in the arousal index are determined by chronic stress. It possibly could be reflection of increased activity in the brain structures by ascending activation caused by different adverse factors. At the same time, a considerable increase in REM 
stage fraction in the total sleep structure is an adaptive reaction to prolonged exposure to psychogenic factors. Thus, specific sleep features in adolescents with hypertension indicate the presence of psychophysiological adaptation. In this case, psychoemotional factors affect mainly the REM organization. This confirms the most widely accepted theories of sleep function, sleep mechanisms and brain organization $[17,18]$.

\section{Competing interests}

The authors declare that they have no competing interests.

\section{References}

1. Danaei G, Finucane MM, Lin JK, Singh GM, Paciorek CJ, Cowan MJ, et al. National, regional, and global trends in systolic blood pressure since 1980: systematic analysis of health examination surveys and epidemiological studies with 786 country-years and 5.4 million participants. Lancet 2011; 377(9765):568-577.

2. Bao W, Threefoot SA, Srinivasan SR, Berenson GS. Essential hypertension predicted by tracking of elevated blood pressure from childhood to adulthood: the Bogalusa Heart Study. Am J Hypertens 1995; 8(7):657-65.

3. Sun SS, Grave GD, Siervogel RM, Pickoff AA, Arslanian SS, Daniels SR. Systolic blood pressure in childhood predicts hypertension and metabolic syndrome later in life. Pediatrics. 2007; 119(2):237-46.

4. Dimsdale JE. Psychological stress and cardiovascular disease. J Am Coll Cardiol. 2008; 51(13):1237-46.

5. Esler M. Heart and mind: psychogenic cardiovascular disease. J Hypertens 2009; 27(4):692-5.

6. Claude J. Mental stress, hypertension and the baroreflex: what's new? J Hypertens 2009; 27(1): 31-3.

7. Palagini L, Drake CL, Gehrman P, Meerlo P, Riemann D. Early-life origin of adult insomnia: does prenatal-early-life stress play a role? Sleep med 2015; 16(4):446-56.
8. Winzeler K, Voellmin A, Schäfer V, Meyer AH, Cajochen C, Wilhelm FH, et al. Daily stress, presleep arousal, and sleep in healthy young women: a daily life computerized sleep diary and actigraphy study. Sleep med 2014; 15(3):359-66.

9. Raschke F, Fischer J. "Arousal" in der Schlafmedizin. Somnologie.1997; 2, 59-64 [Article in German]

10. Michels N, Clays E, De Buyzere M, Vanaelst B, De Henauw S, Sioen I. Children's sleep and autonomic function: low sleep quality has an impact on heart rate variability. Sleep 2013; 36(12):1939-46.

11. Knutson KL. Sleep duration and cardiometabolic risk: a review of the epidemiologic evidence. Best Pract Res Clin Endocrinol Metab 2010; 24(5):731-43.

12. Madaeva I, Kolesnikova L, Dolgikh V, Berdina O. Sleep-disordered breathing in 15-year-old boy with arterial hypertension. Respir Med Case Rep 2012; 8: 5-9.

13. Carr M, Nielsen T. Morning rapid eye movement sleep naps facilitate broad access to emotional semantic networks. Sleep 2015; 38(3):433-43.

14. Iber C, Ancoli-Israel S, Chesson A, Quan SF for the American Academy of Sleep Medicine. The AASM Manual for the Scoring of Sleep and Associated Events: Rules, Terminology and Technical Specifications, 1st ed.: Westchester, IL: American Academy of Sleep Medicine, 2007.

15. Gerin W, Chaplin W, Schwartz JE, Holland J, Alter R, Wheeler R et al. Sustained blood pressure increase after an acute stressor: the effects of the 11 September 2001 attack on the New York City World Trade Center. J Hypertens 2005; 23(2):279-84.

16. Trudel-Fitzgerald C, Boehm J, Kivimaki M, Kubzansky L. Taking the tension out of hypertension: a prospective study of psychological well being and hypertension J Hypertens 2014; 32(6):1222-8.

17. Shneerson JM. Sleep medicine: a guide to sleep and its disorders. 2nd ed. Blackwell Publishing Ltd; 2005.

18. Kryger MH, Roth T, Dement WC. Principles and Practice of Sleep Medicine. 5th Ed. Saunders; 2011. 